\title{
Using Virtual Reality to Improve Antiretroviral Therapy Adherence in the Treatment of HIV: Open-Label Repeated Measure Study
}

Omer Liran $^{1}$, MD; Robert Dasher ${ }^{1}, \mathrm{MD}$; Kevin Kaeochinda ${ }^{2}, \mathrm{PhD}$

${ }^{1}$ Department of Psychiatry and Biobehavioral Sciences, David Geffen School of Medicine at University of California - Los Angeles, Los Angeles, CA, United States

${ }^{2}$ Department of Psychology, Marymount California University, Rancho Palos Verdes, CA, United States

\section{Corresponding Author:}

Omer Liran, MD

Department of Psychiatry and Biobehavioral Sciences

David Geffen School of Medicine at University of California - Los Angeles

10833 Le Conte Ave

Los Angeles, CA, 91604

United States

Phone: 1 (310) 8256373

Email: oliran@ucla.edu

\section{Abstract}

Background: Nonadherence to HIV medications is a serious unsolved problem and is a major cause of morbidity and mortality in the HIV-positive population. Although treatment efficacy is high if compliance is greater than $90 \%$, about $40 \%$ of people with HIV do not meet this threshold.

Objective: This study aimed to test a novel approach to improve medication adherence by using a low-cost virtual reality (VR) experience to educate people with HIV about their illness. We hypothesized that people with HIV would be more likely to be compliant with the treatment following the 7-minute experience and, therefore, should have decreasing viral load (VL), increasing cluster of differentiation $4^{+}\left(\mathrm{CD} 4^{+}\right)$cell counts, and improved self-reported adherence.

Methods: We showed the VR experience to 107 participants with HIV at a county hospital in Los Angeles, California. Participants were asked to self-report how often they take their medications on a Likert-scale. The self-reported question (SRQ) was given before and at least 2 weeks after the VR experience. We also compared VL and CD $4^{+}$cell counts before and on average 101 days after the experience. VL and $\mathrm{CD}^{+}{ }^{+}$were obtained per the clinic's standard care protocol. Two-tailed paired $t$ tests were performed on the initial and follow-up SRQ scores, VL, and $\mathrm{CD}^{+}$. We restricted the $\mathrm{CD} 4^{+}$analysis to participants who had a pre-CD4 ${ }^{+}$ below normal (defined as 500 cells $/ \mathrm{mm}^{3}$ ). To reduce the possibility that VL were trending down and CD4 ${ }^{+}$were trending up regardless of the VR experience, 2 serial VL and $\mathrm{CD}^{+}$obtained before the experience were also compared and analyzed. Immediately following the VR experience, participants were given a 4-question Likert-type postexperience questionnaire (PEQ) that assessed their opinions about the experience.

Results: SRQ scores improved from pre to post experience with high significance $(P<.001)$. VL decreased from pre to post experience by $0.38 \log _{10}$ copies $/ \mathrm{mL}(95 \% \mathrm{CI} 0.06-0.70 ; P=.02)$. In contrast, the 2 serial VL obtained before the experience showed no statistically significant changes. There was also a statistically significant increase in $\mathrm{CD}^{+}\left(95 \% \mathrm{CI}-3.4\right.$ to -54.3 cells $/ \mathrm{mm}^{3}$; $P=.03)$. Analysis of the PEQ revealed that VR was comfortable for almost all of the participants and that most participants believed the experience to be educational and that it would improve their medication adherence.

Conclusions: The findings suggest that the low-cost VR experience caused an increased rate of antiretroviral therapy adherence that resulted in a decrease of VL and an increase of $\mathrm{CD} 4^{+}$. Further studies are required to explore the duration of this effect and whether these results are generalizable to other treatment settings and populations.

(Interact J Med Res 2019;8(2):e13698) doi: 10.2196/13698

\section{KEYWORDS}

HAART; technology; virtual reality; medication adherence; viral load; education 


\section{Introduction}

\section{Background}

HIV is a serious medical illness with significant morbidity and mortality. Advances in treatment have continued to progress with improved regimens both in terms of efficacy and tolerability and in terms of convenience in the form of combination medications in a once- or twice-daily pill known as highly active antiretroviral therapy (HAART). Adherence to HAART has been shown to be correlated with survival $[1,2]$ and quality of life [3]. Primarily because of HAART, HIV is now widely regarded as a chronic and manageable infection [4]. Treatment efficacy, defined as a decrease in viral load (VL), is highly correlated with an almost perfect adherence rate to HAART of at least 90 to $95 \%[5,6]$. However, about $40 \%$ of HIV-positive patients have adherence rates to HAART below $90 \%[7,8]$.

Several factors have been identified that correlate to poor medication adherence including homelessness [9-11], comorbid mental illness [12,13], and active substance use [14,15]. In addition, health literacy has been shown to be an independent predictor for HAART adherence [16,17]. A survey of Medicare patients revealed that $34 \%$ of English-speaking and $54 \%$ of Spanish-speaking respondents had inadequate or marginal health literacy [18]. Compounding to this challenge, a study found that although physicians frequently believe that they are using nontechnical terms when communicating with their patients, they actually used nontechnical language in only $12 \%$ of encounters [19]. Moreover, a study of audiotaped encounters between patients and physicians revealed that there was a discussion about the patient's degree of understanding in only $2 \%$ of the encounters [20]. These data suggest that changes to how patients are educated about their illness may be needed to optimize medication adherence rates.

Virtual reality (VR) has recently emerged as an effective tool in several branches of medicine [21-26]. Recent advances in VR head-mounted displays (HMDs) have made their use increasingly comfortable, affordable, and immersive [27]. VR radically differs from most other media because it can create a level of immersion that produces a feeling of presence - a "sense of being there" [28]. Due to this distinct experiential quality, VR can augment learning with an immersive experience. In addition, VR has been shown to improve learning outcome gains [29-31], and, compared with educational videos, VR has been shown to increase engagement, positive emotions, and remembering of the presented information [32,33]. In fact, an increasing number of classrooms are utilizing VR technology to provide unique and effective educational experiences for their students [34,35].

\section{Objectives}

In light of this trend, the aim of this study was to investigate the effects of an educational VR experience on HAART adherence in people with HIV. Specifically, people with HIV were enrolled at a county clinic to undergo an interactive VR experience that educates them about the importance of HAART adherence. The participants were asked to self-report how often they take their HAART medications on a Likert-scale. To verify the self-reported compliance, pre- and post- HIV VL and CD4 ${ }^{+}$ cell counts were obtained from the participants' digital chart. In addition, second pre- VL and CD4+ were obtained to detect any trends before the VR experience. Participants also completed a post experience questionnaire (PEQ; Multimedia Appendix 1) that assessed their immediate reaction to the VR experience with regard to its novelty, comfort, educational value, and perceived effectiveness.

\section{Methods}

\section{Participants}

From February to September 2018, 107 HIV-infected participants were recruited from Olive View-University of California, Los Angeles (UCLA) Medical Center's HIV clinic in Los Angeles, California. To enroll, participants had to be diagnosed with HIV, be on HAART, be at least 18 years of age, be fluent in English or Spanish, and have no major uncorrectable problems with vision or hearing. There were no selection criteria for initial VL, $\mathrm{CD}^{+}$, or HAART regimen. Participants were continuously recruited from the clinic until the study's predetermined time for access to the clinic elapsed. The institutional review board at Olive View-UCLA Medical Center approved the study. Each participant signed a written informed consent. There were no financial incentives for enrolling in the study.

\section{Interventions}

A 7-minute interactive 3-dimensional educational VR experience was created that illustrates a simplified version of the mechanisms of immune cells, HIV, and antiretroviral medications. We used a Dell Windows Mixed Reality HMD. Research assistants helped place the HMD on the participants' head and adjusted it for optimal clarity and comfort. Participants required no training before the VR experience. The English and Spanish versions of the VR experience had different narrators but otherwise all participants had the same VR experience.

The narrator begins by introducing a virtual person with HIV named Dave and explaining that Dave is made up of cells. A magnifying glass moves to show Dave's skin cells (Multimedia Appendix 2). The experience then virtually transports the participant into one of Dave's arteries. Red blood cells can be seen traveling through the artery when a single rod-shaped bacterium swims nearby (Multimedia Appendix 3). For dramatic visual effect, the bacterium is seen releasing green particles representing poison into the artery. Intense music ensues when a white blood cell (WBC) chases the bacterium, which it eventually engulfs (Multimedia Appendix 4). A single HIV then enters the scene, gets inserted into the WBC, and makes many copies of itself until the WBC bursts (Multimedia Appendix 5). With no WBCs around, many bacteria swim freely and release the green poisonous particles. The artery gradually turns green, signifying that Dave is sick (Multimedia Appendix 6). The scene resets and the narrator says, "Let's see what happens when Dave remembers to take his medications." Hopeful music plays and the narrator encourages the participant to press a button to release "a dose of life-saving medication." When the participant presses the button, medication in the form of gold particles 
enters the artery and creates a shield around the WBC (Multimedia Appendix 7). HIV again tries to attack the WBC but gets repulsed by the shield. The participant is asked to press the button several more times to give more medication as more HIV attempt to attack the WBC (Multimedia Appendix 8). In conclusion, the narrator explains that although Dave feels fine, he is required to continue taking his medications to keep the shield active.

\section{Data Collection}

Participants were asked to self-report how often they take their medications on a Likert-scale. This SRQ was asked just before the VR experience and again at least 2 weeks post experience. The initial SRQ was asked in a face-to-face interview, while the follow-up was asked either by phone or with another face-to-face interview. Immediately following the experience, a PEQ was administered.

$\mathrm{VL}$ and $\mathrm{CD}^{+}$cell counts were drawn as per standard clinic protocol. Both the treating physician who ordered the labs and the laboratory were blinded as to which patients were enrolled in the study. Post-, pre-, and second pre-VL/CD4 ${ }^{+}$were recorded from the participants' digital chart. Given that blood concentrations of HIV ribonucleic acid are expected to decrease rapidly in the first 2 weeks after HAART initiation [36,37], post-VL/CD $4^{+}$were defined as the first labs that were obtained at least 14 days post experience, whereas pre-VL/CD4 ${ }^{+}$were defined as the most recent labs that were obtained before or on the same day as the experience. Finally, second pre-VL/CD $4^{+}$ were defined as the most recent labs that were obtained before the pre-VL/CD4 ${ }^{+}$. All identifying information was removed to protect the privacy of the participants. Demographic data obtained from each participant were age, gender, and primary spoken language.

\section{Data Analysis}

All analyses were performed by use of IBM SPSS software, version 22. The raw VL were converted to a logarithmic scale because of the large variance in the data. Spearman correlation was performed on the initial SRQ scores and pre-VL. A 2-tailed paired $t$ test analysis was performed to compare the initial and follow-up SRQ scores. A 2-tailed paired $t$ test was also performed to compare pre- to post-VL, and pre- to post-CD4 ${ }^{+}$. To assess for the possibility that the VL were decreasing even before the VR experience, a 2-tailed paired $t$ test was performed on the second pre-VL and pre-VL. For the $\mathrm{CD} 4^{+}$analysis, only participants who had below normal pre-CD4 ${ }^{+}$(defined as 500 cells $/ \mathrm{mm}^{3}$ ) were included. Participants who did not have pre-VL, second pre-VL, or post-VL were excluded from this analysis. Finally, the PEQ was correlated with age using Spearman correlation.

\section{Results}

Descriptive statistics were computed and compiled in Table 1. There were no significant gender- or age-related differences in terms of SRQ scores or VL. Out of 107 participants, 28 were excluded because 11 did not have a second pre-VL and 17 did not have a post-VL recorded by the time data collection has concluded. There were no demographic differences between the 28 excluded participants and the remaining 79 participants.

Out of the 79 participants, 4 did not complete the initial SRQ correctly and therefore were excluded from SRQ statistics. Of the remaining 75 participants, 69\% (52/75) were identified as high adherers (score $5 / 5$ on Likert-scale), 15\% (11/75) as medium adherers (score 4), and 16\% (12/75) as low adherers (score $<4)$. A total of 8 participants did not complete the follow-up SRQ because they were both unreachable by phone and were unavailable for follow-up face-to-face interviews. Out of 67 participants who completed the follow-up SRQ, 90\% $(60 / 67)$ were identified as high adherers, $6 \%(4 / 67)$ as medium adherers, and 4\% (3/67) as low adherers. The initial SRQ scores were shown to be correlated with pre-VL $\left(\mathrm{n}=75, r_{\mathrm{s}}=0.316\right.$; $P=.006)$. Likewise, the follow-up SRQ scores were shown to be correlated with post-VL $\left(\mathrm{n}=65, r_{\mathrm{s}}=0.549 ; P<.001\right)$. SRQ scores improved very significantly $(95 \%$ CI .24-.70, $P<.001)$ from pre to post VR experience. Table 2 summarizes participants' transitions from pre to post SRQ. There were not enough data to analyze statistical differences between the 2 modalities used to collect the SRQ (face-to-face and phone interviews); however, other studies suggest that they should be highly correlated [38-40].

Comparison of pre-VL to post-VL showed an average decrease of $0.38 \log _{10}$ copies/mL (95\% CI 0.06-0.70; $P=.02$ ). On the other hand, analysis of second pre-VL and pre-VL showed no statistically significant changes $(95 \% \mathrm{CI}-0.40$ to $0.24 ; P=.62$; Figure 1). The difference between these 2 measurements was highly significant $(P=.01)$. The medians for second pre-, pre-, and post-VL were all 0.

When taken as a whole, there was no statistically significant difference in pre- to post-CD $4^{+}$. However, when only participants who had a pre-CD $4^{+}$below normal (defined as 500 cells $/ \mathrm{mm}^{3}$ ) were included in the analysis, there was a statistically significant increase from pre- to post-CD4 ${ }^{+}(95 \% \mathrm{CI}-54.3$ to $-3.4 ; P=.03)$. Conversely, there was no significant $\mathrm{CD} 4^{+}$count difference between second-pre and pre-CD4 ${ }^{+}(95 \% \mathrm{CI}-56.2$ to $42.6 ; P=.78)$. The medians for second pre-, pre-, and post-CD $4^{+}$were 285,301 , and 323 , respectively.

On average, the pre-VL were drawn 60 days $(\mathrm{SD}=74)$ before the VR experience. A total of 10 participants had their pre-VL drawn on the day of the VR experience, thereby accounting for this non-normal distribution. The post-VL were drawn on average 101 days $(\mathrm{SD}=62)$ after the VR experience. The average interval from second pre-VL to pre-VL was 141 days $(\mathrm{SD}=90)$.

None of the questions on the PEQ were significantly correlated with age. None of the participants reported that the VR experience was uncomfortable. Only 2 participants disagreed that they learned something new about their immune system, HIV, or their medications. Finally, 100 participants (94\%) agreed or strongly agreed that they are more likely to take their medications because of the VR experience (Table 3). 
Table 1. Demographic characteristics of the overall sample and the analyzed group. There were no statistically significant group differences in gender, age, or language.

\begin{tabular}{lll}
\hline Demographics & Overall sample $(\mathrm{N}=107), \mathrm{n}(\%)$ & Analyzed group $(\mathrm{n}=79), \mathrm{n}(\%)$ \\
\hline Gender & $83(77.6)$ & $59(75)$ \\
Male & $24(22.4)$ & $20(25)$ \\
Female & & $25(32)$ \\
Age (years) & $31(29.0)$ & $21(27)$ \\
$18-39$ & $29(27.1)$ & $26(33)$ \\
$40-49$ & $34(31.8)$ & $7(9)$ \\
$50-59$ & $13(12.1)$ & \\
$60+$ & & $74(94)$ \\
Language & $100(93.5)$ & $5(6)$ \\
English & $7(6.5)$ & \\
Spanish & & \\
\hline
\end{tabular}

Table 2. Number of patients transitioning from low, medium, or high adherence groups in the pre self-reported question (SRQ) to the post SRQ ( $\mathrm{n}=67$ ). High adherence was defined as SRQ score 5/5; medium adherence was defined as SRQ score 4; low adherence was defined as SRQ score $<4$.

\begin{tabular}{|c|c|c|c|c|}
\hline Self-Reported Questionnaire adherence score & Post low, n (\%) & Post medium, n (\%) & Post high, n (\%) & Total, n (\%) \\
\hline Pre low & $3(4)$ & $1(1)$ & $8(12)$ & $12(18)$ \\
\hline Pre medium & $0(0)$ & $3(4)$ & $6(9)$ & $9(13)$ \\
\hline Pre high & $0(0)$ & $0(0)$ & $46(69)$ & $46(69)$ \\
\hline Total & $3(4)$ & $4(6)$ & $60(90)$ & $67(100)$ \\
\hline
\end{tabular}

Figure 1. The change $\log 10(\mathrm{VL})$ from before to after the virtual reality experience was significant (green, $\mathrm{P}=.02$ ). On the other hand, the change from the 2 viral loads prior to the experience was nonsignificant (orange, $\mathrm{P}=.62$ ). The difference between the 2 measurements is highly significant $(\mathrm{P}=.01$ ). VL: viral loads.

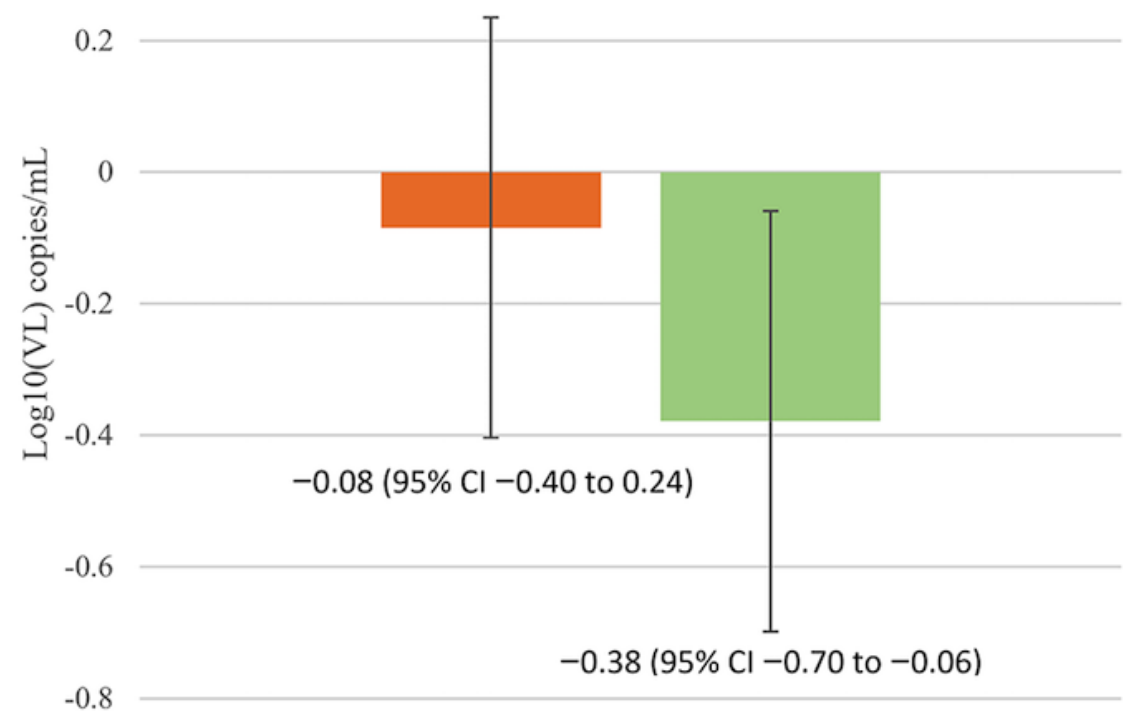

a Second Pre-VL to Pre-VL

m Pre-VL to Post-VL 
Table 3. Responses to the Postexperience Questionnaire (PEQ). Question 1: Virtual Reality is a new experience for me; Question 2: The experience was comfortable; Question 3: I learned something new about my immune system; Question 4: I am now more likely to take my HIV medications. $\mathrm{N}=106$.

\begin{tabular}{lllll}
\hline Post-Experience Questionnaire & Question 1, n (\%) & Question 2, n (\%) & Question 3, n (\%) & Question 4, n (\%) \\
\hline Agree or strongly agree & $91(86)$ & $105(99)$ & $92(87)$ & $100(94)$ \\
Strongly disagree, disagree, or neutral & $15(14)$ & $1(1)$ & $14(13)$ & $6(6)$ \\
\hline
\end{tabular}

\section{Discussion}

\section{Principal Findings}

When taken together, several points of evidence strongly suggest that participants indeed were more compliant with their HAART medications because of the VR experience: (1) the SRQ scores were correlated with VL, (2) the SRQ scores improved from pre to post experience, (3) the VL decreased from pre to post experience but not from serial VL obtained before the experience, (4) the $\mathrm{CD}^{+}$cell counts improved from pre to post experience but not from serial counts obtains before the experience, and (5) almost all participants (94\%) answered on the PEQ that they are more likely to take their medications because of the VR experience.

\section{Limitations}

Although these preliminary results are promising, a number of limitations need to be addressed. First, the study did not randomize participants and no controls were used. Future studies should ideally use a placebo-controlled design. Second, the study was conducted only at a county clinic and therefore may not necessarily be generalizable to other settings or populations. Third, the VL and $\mathrm{CD} 4^{+}$counts were obtained as per the clinic's standard of care. A superior study would control the timing of the blood draws to more thoroughly account for extraneous variables in the data. Fourth, the duration for which increased
HAART adherence is maintained is unclear. A longitudinal study with more participants would allow for more robust statistical analyses. It would also be worth testing whether repeating the experience every few months can maintain improved compliance over time. Finally, collecting further demographic data on, for example, health literacy, homelessness, substance use, and comorbid mental illness could yield interesting correlations that may help advise which subpopulations would be most likely to benefit from the VR experience.

\section{Conclusions}

This study suggests that patient education using VR is effective for increasing HAART adherence. If the results are confirmed, VR's effectiveness and relative low cost offers a great opportunity for clinics to implement a simple solution that may improve both the morbidity and mortality of their patients. Future studies should attempt to generalize the results to other settings, populations, and illnesses-especially those in which patients feel healthy and may not feel the need for taking their medications as scheduled. Compared with other traditional media platforms such as videos, VR is more immersive and thus has a greater positive emotional impact, which can improve engagement and learning. VR is rapidly becoming more accessible, affordable, and immersive, and more studies are needed to further explore opportunities for using this maturing technology for improving peoples' lives.

\section{Acknowledgments}

No external funding sources were used. The VR hardware and accessories were purchased by the authors. The VR experience software was created by the primary author. The data were collected by volunteer research assistants. Participants were not compensated monetarily.

\section{Authors' Contributions}

OL designed the research study, created the VR experience, and authored the article. OL and RD performed the research. KK and OL analyzed the data.

\section{Conflicts of Interest}

OL may decide to patent some aspects of the software he developed. RD and KK declare no conflicts of interest.

\section{Multimedia Appendix 1}

Postexperience questionnaire.

[PDF File (Adobe PDF File), 135KB-Multimedia Appendix 1]

\section{Multimedia Appendix 2}

Dave's skin is made up of cells.

[PDF File (Adobe PDF File), 1MB-Multimedia Appendix 2] 


\section{Multimedia Appendix 3}

A bacterium swims inside an artery.

[PDF File (Adobe PDF File), 1MB-Multimedia Appendix 3]

\section{Multimedia Appendix 4}

A white blood cell engulfs the poison-producing bacterium.

[PDF File (Adobe PDF File), 1MB-Multimedia Appendix 4]

\section{Multimedia Appendix 5}

HIV enters the white blood cell, makes copies of itself, and causes the cell to explode.

[PDF File (Adobe PDF File), 1MB-Multimedia Appendix 5]

\section{Multimedia Appendix 6}

Without the white blood cells, bacteria can produce poison without deterrence.

[PDF File (Adobe PDF File), 1MB-Multimedia Appendix 6]

\section{Multimedia Appendix 7}

The medication produces a shield around the white blood cell.

[PDF File (Adobe PDF File), 1MB-Multimedia Appendix 7]

\section{Multimedia Appendix 8}

HIV cannot penetrate the medicated white blood cell.

[PDF File (Adobe PDF File), 1MB-Multimedia Appendix 8]

\section{References}

1. Fischl MA, Richman DD, Grieco MH, Gottlieb MS, Volberding PA, Laskin OL, et al. The efficacy of azidothymidine (AZT) in the treatment of patients with AIDS and AIDS-related complex. A double-blind, placebo-controlled trial. N Engl J Med 1987 Jul 23;317(4):185-191. [doi: 10.1056/NEJM198707233170401] [Medline: $\underline{3299089]}$

2. Graham NM, Zeger SL, Park LP, Vermund SH, Detels R, Rinaldo CR, et al. The effects on survival of early treatment of human immunodeficiency virus infection. N Engl J Med 1992 Apr 16;326(16):1037-1042. [doi:

10.1056/NEJM199204163261601] [Medline: 1347907]

3. Jelsma J, Maclean E, Hughes J, Tinise X, Darder M. An investigation into the health-related quality of life of individuals living with HIV who are receiving HAART. AIDS Care 2005 Jul 18;17(5):579-588. [doi: 10.1080/09540120412331319714] [Medline: 16036244]

4. Chesney M. Adherence to HAART regimens. AIDS Patient Care STDS 2003 Apr;17(4):169-177. [doi: 10.1089/108729103321619773] [Medline: 12737640]

5. Carpenter CCJ, Fischl MA, Hammer SM, Hirsch MS, Jacobsen DM, Katzenstein DA, et al. Antiretroviral therapy for HIV infection in 1998: updated recommendations of the International AIDS Society-USA Panel. J Am Med Assoc 1998 Jul 1;280(1):78-86. [Medline: 9660368 ]

6. Bangsberg DR, Hecht FM, Clague H, Charlebois ED, Ciccarone D, Chesney M, et al. Provider assessment of adherence to HIV antiretroviral therapy. J Acquir Immune Defic Syndr 2001 Apr 15;26(5):435-442. [Medline: 11391162]

7. Pop-Eleches C, Thirumurthy H, Habyarimana J, Zivin J, Goldstein M, de Walque D, et al. Mobile phone technologies improve adherence to antiretroviral treatment in a resource-limited setting: a randomized controlled trial of text message reminders. AIDS 2011 Mar 27;25(6):825-834 [FREE Full text] [doi: 10.1097/QAD.0b013e32834380c1] [Medline: 21252632]

8. Ortego C, Huedo-Medina TB, Llorca J, Sevilla L, Santos P, Rodríguez E, et al. Adherence to highly active antiretroviral therapy (HAART): a meta-analysis. AIDS Behav 2011 Oct;15(7):1381-1396. [doi: 10.1007/s10461-011-9942-x] [Medline: 21468660]

9. Kidder D, Wolitski R, Campsmith M, Nakamura GV. Health status, health care use, medication use, and medication adherence among homeless and housed people living with HIV/AIDS. Am J Public Health 2007 Dec;97(12):2238-2245. [doi: 10.2105/AJPH.2006.090209] [Medline: 17971562] 
10. Leaver C, Bargh G, Dunn J, Hwang S. The effects of housing status on health-related outcomes in people living with HIV: a systematic review of the literature. AIDS Behav 2007 Nov;11(6 Suppl):85-100. [doi: 10.1007/s10461-007-9246-3] [Medline: 17682940]

11. Lee W, Milloy M, Nosova E, Walsh J, Kerr T. Predictors of antiretroviral adherence self-efficacy among people living with HIV/AIDS in a Canadian setting. J Acquir Immune Defic Syndr 2019 Jan 1;80(1):103-109. [doi:

10.1097/QAI.0000000000001878] [Medline: 30300214]

12. Kemppainen J, Levine R, Buffum M, Holzemer W, Finley P, Jensen P. Antiretroviral adherence in persons with HIV/AIDS and severe mental illness. J Nerv Ment Dis 2004 Jun;192(6):395-404. [Medline: 15167402]

13. DiMatteo MR, Lepper HS, Croghan TW. Depression is a risk factor for noncompliance with medical treatment: meta-analysis of the effects of anxiety and depression on patient adherence. Arch Intern Med 2000 Jul 24;160(14):2101-2107. [Medline: 10904452]

14. Tucker J, Burnam M, Sherbourne C, Kung F, Gifford A. Substance use and mental health correlates of nonadherence to antiretroviral medications in a sample of patients with human immunodeficiency virus infection. Am J Med 2003 May;114(7):573-580. [Medline: 12753881]

15. Lemons A, DeGroote N, Peréz A, Craw J, Nyaku M, Broz D, et al. Opioid misuse among HIV-positive adults in medical care: results from the Medical Monitoring Project, 2009-2014. J Acquir Immune Defic Syndr 2019 Feb 1;80(2):127-134. [doi: 10.1097/QAI.0000000000001889] [Medline: 30383590]

16. Kalichman S, Ramachandran B, Catz S. Adherence to combination antiretroviral therapies in HIV patients of low health literacy. J Gen Intern Med 1999 May;14(5):267-273 [FREE Full text] [doi: 10.1046/j.1525-1497.1999.00334.x] [Medline: $\underline{10337035]}$

17. Fogarty L, Roter D, Larson S, Burke J, Gillespie J, Levy R. Patient adherence to HIV medication regimens: a review of published and abstract reports. Patient Educ Couns 2002 Feb;46(2):93-108. [Medline: 11867239]

18. Gazmararian JA, Baker DW, Williams MV, Parker RM, Scott TL, Green DC, et al. Health literacy among Medicare enrollees in a managed care organization. J Am Med Assoc 1999 Feb 10;281(6):545-551. [Medline: 10022111]

19. Williams MV, Davis T, Parker RM, Weiss BD. The role of health literacy in patient-physician communication. Fam Med 2002 May;34(5):383-389. [Medline: 12038721 ]

20. Waitzkin H. Information giving in medical care. J Health Soc Behav 1985 Jun;26(2):81-101. [Medline: 4031436]

21. Pourmand A, Davis S, Lee D, Barber S, Sikka N. Emerging utility of virtual reality as a multidisciplinary tool in clinical medicine. Games Health J 2017 Oct;6(5):263-270. [doi: 10.1089/g4h.2017.0046] [Medline: 28759254]

22. Silva J, Southworth M, Raptis C, Silva J. Emerging applications of virtual reality in cardiovascular medicine. JACC Basic Transl Sci 2018 Jun;3(3):420-430 [FREE Full text] [doi: 10.1016/j.jacbts.2017.11.009] [Medline: 30062228]

23. Ferrer-Garcia M, Gutiérrez-Maldonado J, Riva G. Virtual reality based treatments in eating disorders and obesity: a review. J Contemp Psychother 2013 Jun 25;43(4):207-221. [doi: 10.1007/s10879-013-9240-1]

24. Freeman D, Reeve S, Robinson A, Ehlers A, Clark D, Spanlang B, et al. Virtual reality in the assessment, understanding, and treatment of mental health disorders. Psychol Med 2017 Oct;47(14):2393-2400 [FREE Full text] [doi: 10.1017/S003329171700040X] [Medline: 28325167]

25. Farahani N, Post R, Duboy J, Ahmed I, Kolowitz B, Krinchai T, et al. Exploring virtual reality technology and the Oculus Rift for the examination of digital pathology slides. J Pathol Inform 2016;7(1):22 [FREE Full text] [doi: 10.4103/2153-3539.181766] [Medline: 27217972]

26. Ota D, Loftin B, Saito T, Lea R, Keller J. Virtual reality in surgical education. Comput Biol Med 1995 Mar;25(2):127-137. [Medline: $\underline{7554831]}$

27. Slater M. Grand challenges in virtual environments. Front Robot AI 2014 May 27;1. [doi: 10.3389/frobt.2014.00003]

28. Steuer J. Defining virtual reality: dimensions determining telepresence, communication in the age of virtual reality. $\mathbf{J}$ Communication 1992;42(4):73-93. [doi: 10.1111/j.1460-2466.1992.tb00812.x]

29. Ekstrand C, Jamal A, Nguyen R, Kudryk A, Mann J, Mendez I. Immersive and interactive virtual reality to improve learning and retention of neuroanatomy in medical students: a randomized controlled study. CMAJ Open 2018 Feb 23;6(1):E103-E109 [FREE Full text] [doi: 10.9778/cmajo.20170110] [Medline: 29510979]

30. Merchant Z, Goetz ET, Cifuentes L, Keeney-Kennicutt W, Davis TJ. Effectiveness of virtual reality-based instruction on students' learning outcomes in K-12 and higher education: a meta-analysis. Comput Educ 2014 Jan;70:29-40. [doi: 10.1016/i.compedu.2013.07.033]

31. Abulrub AG, Attridge AN, Williams MA. Virtual reality in engineering education: the future of creative learning. Int J Emerg Technol Learn 2011 Dec 2;6(4):751-757. [doi: 10.3991/ijet.v6i4.1766]

32. Allcoat D, von Mühlenen A. Learning in virtual reality: effects on performance, emotion and engagement. Res Learn Technol 2018 Nov 27;26. [doi: 10.25304/rlt.v26.2140]

33. Krokos E, Plaisant C, Varshney A. Virtual memory palaces: immersion aids recall. In: Virtual Reality. London: Springer; May 16, 2018:1-15.

34. Dede C, Jacobson J, Richards J. Virtual, Augmented, and Mixed Realities in Education. Singapore: Springer; Nov 16, 2017.

35. Kennedy E. CNN.: CNN; 2018. Can virtual reality revolutionize education? URL: https://www.cnn.com/2018/11/01/health/ virtual-reality-education/index.html [accessed 2019-05-29] [WebCite Cache ID 78kGy9Xey] 
36. Wei X, Ghosh S, Taylor M, Johnson V, Emini E, Deutsch P, et al. Viral dynamics in human immunodeficiency virus type 1 infection. Nature 1995 Jan 12;373(6510):117-122. [doi: 10.1038/373117a0] [Medline: 7529365]

37. Ho D, Neumann A, Perelson A, Chen W, Leonard J, Markowitz M. Rapid turnover of plasma virions and CD4 lymphocytes in HIV-1 infection. Nature 1995 Jan 12;373(6510):123-126. [doi: 10.1038/373123a0] [Medline: 7816094]

38. Fenig S, Levav I, Kohn R, Yelin N. Telephone vs face-to-face interviewing in a community psychiatric survey. Am J Public Health 1993 Jun;83(6):896-898. [doi: 10.2105/ajph.83.6.896] [Medline: 8498632]

39. Sturges J, Hanrahan K. Comparing telephone and face-to-face qualitative interviewing: a research note. Qual Res 2016 Aug 15;4(1):107-118. [doi: 10.1177/1468794104041110]

40. Nebot M, Celentano DD, Burwell L, Davis A, Davis M, Polacsek M, et al. AIDS and behavioural risk factors in women in inner city Baltimore: a comparison of telephone and face to face surveys. J Epidemiol Community Health 1994 Aug 1;48(4):412-418 [FREE Full text] [doi: 10.1136/jech.48.4.412] [Medline: 7964343]

\author{
Abbreviations \\ CD4+: cluster of differentiation 4+ \\ HAART: highly active antiretroviral therapy \\ HMD: head-mounted display \\ PEQ: post experience questionnaire \\ SRQ: Self-reported question \\ UCLA: University of California, Los Angeles \\ VL: viral load \\ VR: virtual reality \\ WBC: white blood cell
}

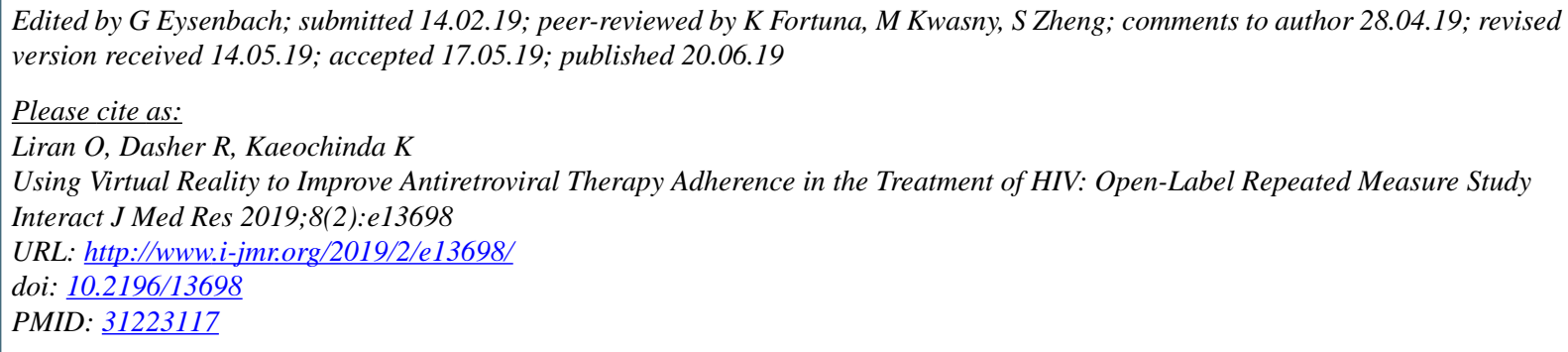

COmer Liran, Robert Dasher, Kevin Kaeochinda. Originally published in the Interactive Journal of Medical Research (http://www.i-jmr.org/), 20.06.2019. This is an open-access article distributed under the terms of the Creative Commons Attribution License (https://creativecommons.org/licenses/by/4.0/), which permits unrestricted use, distribution, and reproduction in any medium, provided the original work, first published in the Interactive Journal of Medical Research, is properly cited. The complete bibliographic information, a link to the original publication on http://www.i-jmr.org/, as well as this copyright and license information must be included. 